\title{
LA CORRESPONDENCIA DEL CARDENAL TORRIGIANI CON EL NUNCIO DE ESPAÑA (1760-1762)
}

\author{
Ana SÁNCHEZ MONTAHUD \\ Universidad de Alicante
}

\begin{abstract}
Resumen
En un momento en el que las relaciones entre Madrid y Roma, presentaban una gran complejidad, la correspondencia entre el Secretario de Estado del Vaticano, Cardenal Torrigiani, y el Nuncio en España permite distinguir los temas que preocuparon a la Santa Sede durante el pontificado de Clemente XIII. La función del Nuncio, como representante del Papa era, por tanto, de vital importancia y el gobierno español, no podía dejar de observarlo, en una actitud de acentuado regalismo, como una injerencia del poder pontificio en sus territorios.
\end{abstract}

\begin{abstract}
In a moment in which the relations between Madrid and Rome were of great complexity, the correspondence between the State Secretary of the Vatican, Cardinal Torrigiani and the nuncio in Spain allows us to distinguish the topics that concerned to the Papal seat during the reign of Clement XIII. The function of the nuncio, as a representative of the Pope, was in fact of a vital importance, and the Spanish government could not help noticing it -in an attitude of stressed defence of the royal prerogatives- as an interference of the pontifical power in its territories.
\end{abstract}

El estudio de las relaciones epistolares entre la Secretaría de Estado Vaticano y las Nunciaturas de los distintos países católicos europeos en el siglo XVIII ofrece un cuadro vivo de la situación política y social del continente. El motivo de este hecho estriba en que las cartas recogían los diferentes temas que constituían la actualidad del momento. Este trabajo se centra en el análisis de las cifras en las que el Secretario de Estado Vaticano, Cardenal Luigi Maria Torrigiani, contestaba al Nuncio Apostólico en España, que es la documentación estudiada hasta el momento dentro de un más amplio trabajo de investigación, orientado a la realización de la tesis doctoral ${ }^{\text {. }}$

1. Archivio Segreto Vaticano, Segreteria di Stato, Sezione Spagna, volumen 431 . En dicho volumen está contenida la correspondencia con el Nuncio Apostólico en España de los años 1758 a 1762. 
En el período elegido, la Nunciatura española fue ocupada por Monseñor Girolamo Spinola (desde el 5 de octubre de 1754 al 20 de julio de 1760), sucediéndole Monseñor Lazzaro Opizio Pallavicini. Este prelado había sido con anterioridad Nuncio Apostólico en Nápoles, y en 1760 fue nombrado para ocuparse de la Nunciatura de Madrid $^{2}$.

\section{LA CORRESPONDENCIA CON EL NUNCIO SPINOLA}

En su último año en la Nunciatura de Madrid, Spinola mantuvo, como siempre había hecho, una activa comunicación con el Secretario de Estado Torrigiani. Ello motivó que el Secretario le dirigiera una serie de cartas a través de las cuales se observan las principales preocupaciones de Roma. En 1759, habían ocupado un lugar destacado las turbulencias de Portugal y la partida desde Nápoles del futuro Carlos III de España. Este hecho provocaba, además, una lógica inquietud para Roma pues ello llevaría consigo la llegada de nuevos ministros. Eran momentos delicados en los que la prudencia le fue aconsejada una y otra vez al Nuncio por Torrigiani. Los «atentados» que debía sufrir la Santa Sede en Portugal, y entre ellos la expulsión de los jesuitas del reino, llenaban de disgusto a la Santa Sede, que no cesaba de pedir información a Spinola.

En 1760, las cartas de Torrigiani al Nuncio tratan de asuntos diversos. Nápoles sigue siendo el centro de atención del Secretario, además de la posibilidad de la celebración de un Congreso de $\mathrm{Paz}^{3}$. No hay que olvidar que en este momento, Europa estaba inmersa en la Guerra de los Siete Años. España en 1760 no participaba en la misma, y se pensaba en la posibilidad de celebrar un Congreso entre las potencias beligerantes con la actuación del Rey de España como mediador. La Santa Sede ante este rumor no quería quedar aislada de las negociaciones, y deseaba la presencia de un ministro pontificio en ellas que contara con la aprobación de la Corte española, posible árbitro de dicho Congreso. El Nuncio debía emplear todos sus oficios para conseguir esta participación.

En cuanto a Nápoles, el pleito que mantenía un noble napolitano, el barón de Bitetto, con la Cámara Apostólica dio lugar a un conflicto jurisdiccional. Bitetto pedía la liquidación de una deuda contraída con él por Monseñor Clarelli ${ }^{4}$, a cuenta de dicha Cámara. El barón se dirigió en primer lugar a los Tribunales napolitanos. El Nuncio en España debía presionar para que el Rey Carlos apoyase una decisión favorable a la Cámara Apostólica, absolviéndola del pago de la deuda. Si esto no se conseguía, el desprestigio de la Santa Sede estaba asegurado. Igualmente, en Nápoles los constantes menoscabos que sufría el patrimonio eclesiástico a favor del real, llenaron las páginas de la correspondencia de Torrigiani. En este sentido, el caso de la abadía de La Bagnara ${ }^{5}$ estaba en el centro de la disputa entre la Santa Sede y el Reino de Nápo-

2. En 1769, Pallavicini fue Secretario de Estado Vaticano con Clemente XIV y su sucesor, Pío VI hasta 1785 .

3. ASV, Segreteria di Stato, Spagna, vol. 431, cifra del 14 de Febrero de 1760.

4. Monseñor Clarelli era el Presidente de la «Grascia» de Roma. La deuda que motivaba la querella de Bitetto tenía su origen en la compra de aceite al barón napolitano en 1748 (cit. en MAIORINI, M.G., Epistolario di Bernardo Tanucci, vol. IX, Roma, 1985, p. 316).

5. ASV, Segreteria di Stato, Spagna, vol. 431, 2 de Abril de 1760. 
les. Tanucci y la Regencia realizaban toda serie de acciones destinadas a limitar las propiedades eclesiásticas en el Reino. Según cuenta el propio Secretario al Nuncio, en la cifra citada:

«La Abbazia della Bagnara nel Regno di Napoli, dopo varie vicende era stata goduta per lo spazio di più secoli dai Religiosi Domenicani con la giurisdizione quasi episcopale esercitata dal Priore pro tempore di quel convento. Venne in capo l'anno passato ai regi ministri di crederla un padronato regio, e avendo fatta istanza in questa Dateria che si spedissero le Bolle a un certo Abbate Cristiani nominato da S.M., si ebbe dificoltà di accordarle... stava per tenersi una Congregazione deputata da Nostro Signore per esaminare... tutto all'inproviso si seppe che per via di fatto erano stati scacciati tutti $i$ religiosi... e che col mezzo del Vescovo di Cefalù non solo ne era stato messo in possesso il regio nominato Abbate Cristiani, ma anche era investito della giurisdizione della quale abusando... ha commessi dei gravissimi attentati con scandalo... Di questi fatti, come che sucessi negli ultimi momenti del soggiorno di S.M.Cattca. nel Regno..., se ne ebbero le notizie solamente qualche tempo dopo la sua partenza».

La Regencia no quería encontrar remedio «a questo insoportabile desordine» y se excusaban diciendo que, como era algo que había sucedido en tiempos del gobierno de Don Carlos, no podían alterar la situación. Roma no permanecía impasible ante este nuevo ataque y como refería Torrigiani, se envió un Breve al Obispo de Cefalù para amonestarle por su actuación. Este Breve fue considerado por Tanucci, como se indica en la cifra del 8 de mayo de 1760, como «una delle solite insolenze della Corte di Roma». El Nuncio debía procurar que esta queja de Tanucci no influyera en la Corte española, a la que obviamente el Reino de Nápoles comunicaba todas sus acciones. Y con fecha del 17 de julio de 1760, aparece la primera cifra escrita por el Secretario al nuevo Nuncio Apostólico, Pallavicini.

\section{LA CORRESPONDENCIA CON EL NUNCIO PALLAVICINI \\ a) Año 1760}

Fue éste un año especialmente agitado para Roma, según se desprende de la correspondencia de su Secretaría de Estado. Portugal había roto sus relaciones con la Santa Sede y este hecho, motivó que Torrigiani solicitase al Nuncio información sobre cómo se había tomado la ruptura en la Corte española. La aparición de escritos sobre la situación portuguesa ${ }^{6}$, las críticas ante las acciones de la Santa Sede, la actuación del Abate Platel ${ }^{7}$... eran causa de polémica en Europa. Torrigiani dio toda una

6. ASV, Ibídem, Cifra del 2 de Octubre de 1760: «Sará forse capitata copia d'una scrittura intitolata Appendice alle osservazioni sopra la condotta del Ministro di Portogallo... a chi volesse farvi una più esatta riflessione... scoprirebbe ancora una tacita recriminazione contro la nostra Corte. In Roma é stato già da qualcuno spaccitato per un prodotto della Segretaria di Stato, e però ha voluto Nostro Signore che una tal voce si smentisse, e mi ha ordinato d'incaricarne V.Illma».

7. ASV, Ibídem. Dice el Secretario: «Mi vien scritto da Parigi, che l'Abbate Platel, cosí in oggi cambiato dall' antico P. Norberto Capuccino, sia stato destinato confessore del Re di Portogallo; e che Monsignore Vescovo di Soissons, che trovasi ora in Ispagna, stia travagliando per comporre un corso di Teologia per uso di Lisbona. Dalla prima nuova potrà V.Illma. esserne forse inteso... ma della seconda non dubito che possa esserle il tutto già noto, o almeno abbia facilmente la maniera per indagarne il preciso». Cifra del 18 de Septiembre de 1760. El abad Platel, también conocido como el Padre Norberto, entró en los capuchinos en 1716. En 1736 es nombrado procurador general de las misiones extranjeras de Fran- 
serie de instrucciones a Pallavicini para que utilizara sus artes a la hora de defender los intereses de Roma ante la Corte española. Incluso le aconsejó exponer los agravios recibidos al Embajador de Francia, a cambio de las informaciones que pudiera tener $^{8}$. Para el Secretario, el asunto de Portugal era consecuencia de la actuación desorbitada del ministro Pombal, el cual, a pesar de la buena voluntad del Rey, no cesaba de atacar a la Sede Apostólica.

Junto a los sucesos portugueses, este año recoge otro de los temas que Roma no podía dejar de tratar en sus relaciones con España. Éste era el desarrollo de la causa del Venerable Palafox en Roma. España con la llegada de Carlos III al trono reanudó sus pretensiones en torno a la beatificación del Obispo ${ }^{4}$. Según la correspondencia del Cardenal Torrigiani, la Congregación de Ritos estaba llevando a cabo un examen de los escritos de Palafox. Passionei, el Cardenal Ponente de la causa, no dejaba de señalar las premuras que Su Majestad Católica tenía en su resolución. Passionei, uno de los máximos exponentes del grupo jansenista romano, estaba muy interesado en que Palafox, conocido adversario de los jesuitas, fuera beatificado, pues ello supondría un golpe para los defensores de la Compañía. El Rey escribió una carta al Papa exponiéndole su interés y se solicitaba una respuesta a la misma. El problema era, según Torrigiani, que en estos casos no se acostumbraba a responder, archivándose los documentos para hacer honorable mención de los mismos al concluir las causas. El Nuncio, no obstante, podía referir al Rey que:

\section{«Sua Santità non avrà difficoltà di fare un eccezione alla generale consuetudine in questo caso»".}

Alrededor de esta carta regia, entregada por el embajador español Manuel Roda a la Corte romana, se suscitó una curiosa polémica. Hasta España llegó el rumor de que en Roma se dudaba de la autenticidad del documento y el Secretario de Estado, Wall, daba crédito al mismo. Torrigiani escribía en la misma cifra citada anteriormente que:

cia. Partió hacia Pondichéry donde tuvo un importantísimo papel en las discusiones entre jesuitas y capuchinos relativas a los ritos malabares. Regresó a Roma en 1741, y continuó con sus ataques contra la Compañía de Jesús. Comenzó con la redacción de voluminosas memorias donde los jesuitas no salían bien parados. Condenada su obra por Roma, su vida cambió totalmente. Tras diversas vicisitudes, se estableció en Portugal donde secundó la obra política de Pombal. Dejó Lisboa en 1763 y murió en 1769, dejando una voluminosa producción literaria. (Cit. en AMANN, É. Dictionnaire de Théologie catholique, vol. XI, pp. 2040-2043).

8. ASV, Ibidem, Cifra del 15 de Diciembre de 1760.

9. Juan Palafox y Mendoza fue obispo de La Puebla de Los Angeles (México) y de Osma. Era conocido por sus enfrentamientos con los jesuitas. En 1726, se inició su proceso de beatificación, favorecido por los gobemantes españoles. En este intento, chocaron las dos corrientes de pensamiento de la Iglesia del siglo XVIII. En teología, se enfrentaron la escuela tomista y la defendida en Trento por el jesuita Salmerón. En moral, los que defendían la atrición y los que exigían la existencia de la contrición para salvarse. Y además, aparecían los que subrayaban el papel del Papa y los que ponían el acento en la autoridad de los obispos y los concilios. Palafox fue la persona en la que se concentró toda la polémica.Para los jesuitas, era un «jansenista» y para sus defensores merecía ser beatificado, representando también este logro una importante victoria sobre la Compañía. (cit. en MESTRE, A. «Religión y cultura en el siglo XVIII español» en Historia de la Iglesia en España, Tomo IV, BAC, 1979, pp 659-660. Y en LLIDO, J. «José Climent: Filojansenismo y regalismo en la España de Carlos III...» en Anales Valentinos, n. 8, pp. 361-362

10. ASV, Ibidem, Cifra del 30 de Octubre de 1760. 
«Non so comprendere, a chi sia venuta in mente questa supposizione. Vi sono persone che si figurano falsamente, che $i$ Gesuiti stiano assediando Palazzo, e che vi siano ammessi ad ogni confidenza, ad ogni maneggio... avrà voluto far credere ch'essi abbiano procurato di diminuire nell'animo del Papa il credito agli iffici del Re, sotto un frivolo pretesto. Procuri ella disipare tali prevenzioni...».

El Papa, escribía Torrigiani, estaba por encima de cualquier partido o división y se comportaba de forma imparcial.

A la causa por la beatificación de Palafox, se sumaba en este momento otra pretensión de España. Su Majestad Católica presentó una petición al Papa para que confirmara la elección como Patrona de España de la Virgen bajo el título y misterio de Inmaculada Concepción" ". Clemente XIII actuó rápidamente y preparó un esbozo de la bula. En su deseo de complacer al soberano, y esto debía ser bien recalcado por el Nuncio, había utilizado una pequeña estratagema para conceder lo solicitado. Los pontífices anteriores nunca habían unido el atributo de Innaculada a la Concepción, sino a la Virgen. En su cifra del 13 de Noviembre de 1761, Torrigiani es claro sobre este hecho.

"Non ha creduto pertanto Nostro Signore di doversi assolutamente dipartire dal metodo costante tenuto dai suoi Predecessori, ma ha presso una strada di mezzo. Si è fatto pero stendere... un memoriale dal Regio Ministro in nome di Sua Maestà; nel quale gli si é lasciato dive tutto quello che ha voluto, e... si è inserito per extensum nella Bolla, dopo di che si fa che il Papa nella Dispositiva approvi, e conceda quello che si domanda, senza però che nomini Lui espressamente L'Immacolata Concezione. Questo ripiego, como Lei ben vede, salva una certa apparenza, ma nella sostanza non toglie nulla di quello che S.M. potesse mai desiderare...». Roda.

El Rey manifestó su agrado y así lo hizo saber a través de su embajador Manuel

Nápoles, por supuesto, no dejaba de crear dificultades a la Santa Sede. De nuevo, surgía la causa del barón del Bitetto. La Regencia napolitana aprovechó la ocasión para manifestar su disgusto con la Cámara Apostólica y solicitó ser informada para poder así decidir de una forma rápida en este contencioso. El rey de España prefería mostrarse en esta causa en una posición neutral por no aumentar la tirantez con la Santa Sede.

b) 1761

En el año 1761 vuelve a aparecer como tema destacado la causa de Palafox. Nápoles y Portugal fueron también objeto de la atención de la Santa Sede, junto a otras cuestiones de carácter bélico y el proyectado Congreso de Paz de Augsburgo. A su

11. Este es uno de los puntos más delicados de la Mariología. Han sido definidos cuatro dogmas que tienen que ser creídos como artículos de fe: su maternidad divina, su virginidad, su inmaculada concepción y su asunción a los cielos. Los dos primeros fueron establecidos en concilios de la iglesia primitiva y aceptados por la mayoría de los grupos reformados cristianos. Su asunción fue definida por el Papa Pío XII en 1950. En cuanto a la inmaculada concepción, que la libra de toda mancha de pecado original y la eleva sobre el resto de la raza humana, fue proclamado en 1854 por Pío IX (Bula Ineffabilis Deus). Las vicisitudes que esta doctrina experimentó desde sus orígenes en la doctrina cristiana hasta su definición dogmática reflejan los cambios que la propia Iglesia sufría al igual que las opiniones filosóficas (cit. en WARNER, M. Tú sola entre las mujeres, 1991, Madrid, pp. 308-331) 
vez, la polémica nacida en torno al Catecismo de Messenguy y el exequatur regio ocupó gran parte de la correspondencia.

En la causa de Palafox, el Secretario le anunció al Nuncio en España la publicación del Decreto en que se aprobaban los escritos del Obispo de Puebla. Esto era insólito pues se acostumbraba a publicar únicamente los decretos en los que se aprobaban virtudes y milagros. La publicación hizo concebir a la Corte española grandes esperanzas. Mientras, seguían llegando a Roma diferentes manifestaciones de los obispos españoles a favor de la beatificación.

La Corte de Portugal continuaba inquietando a la Santa Sede. Torrigiani refiere, en su cifra del 5 de febrero de 1761, cómo en Roma se había mandado quemar públicamente un libro cuyo autor era o fingía ser un súbdito de la Corona portuguesa. En la obra, se atacaba el informe que fue mandado por la Secretaría de Estado a todos los ministros extranjeros residentes en Roma sobre la expulsión del Nuncio Acciaioli de Portugal y de la salida del embajador portugués en Roma, Francisco de Almeida. Además, justificaba la expulsión del Nuncio de Portugal pues estaba preparando, tras la conjura de los jesuitas, una segunda conspiración en la que le ayudaba Torrigiani. El Secretario relató este hecho al Nuncio Pallavicini para que estuviera preparado ante cualquier recriminación en España. El 29 de octubre de 1761, el Secretario manifestaba su opinión sobre el suplicio y la ejecución a muerte del Padre Malagrida ${ }^{12}$.

Pero los problemas para la Santa Sede no acababan en Portugal. El Reino de Nápoles seguía obstaculizando cualquier acción de la Santa Sede en su territorio. La causa emprendida por el noble napolitano Bitetto que continuaba reclamando su dinero a la Cámara Apostólica seguía sin solución. El Tribunal del Comercio de Nápoles había remitido la causa para una nueva consulta a la Cámara Real napolitana, que Torrigiani imaginaba poco favorable a sus intereses. La causa pasó finalmente a los Tribunales de Roma. Pero los manejos del Cardenal Orsini, que insinuaba el procedimiento irregular de que el Papa recibiera en audiencia al barón para facilitar la resolución del caso, no provocaba en Torrigiani demasiado optimismo, lo que manifestaba en su cifra del 26 de noviembre de 1761. Otra cuestión aparecía ensombreciendo las relaciones de Nápoles con la Santa Sede. Como refiere el propio Secretario:

«Tra le gravissime cure del Pontificato nei tempi presenti e tra le moltissime molestie, che riceve Sua Santità delle cose di Napoli, appunto non vi mancava altro, se non che si attentasse contro i diritti di questa Santa Sede sul medessimo regno. Troverà V.Illma... una memoria, in cui é esposta la causa del Pontificio disgusto, e scontrerà subito l'aggravio intollerabile che riceve la Santa Sede dalla Riversale, o sia Bolla d'Oro che dal Regno di Napoli é stata mandata a Nostro Signore. Si tratta di un regno, che per tanti secoli é stato sempre feudo della Chiesa Romana, e per tale riconosciuto di tanti sovrani, e dal medessimo Re di Spagna, anzi anche dall'istesso Re di Napoli, quando ha richiesta e ricevuta l'investitura. Non può... Sua Santità... per conservare i diritti della Santa Sede, trascurare l'inguria manifestissima che le si reca colla sostanzialissima variazione della Reversale» ${ }^{13}$.

12. ASV, Segretaria di Stato, Spagna, vol. 431. «Ho letta la Relazione compiegata... sull'esecuzione a morte del Padre Malagrida. Ravviso della medessima i vari delitti che gli sono stati imputati, tra quali non si è neppur ommesso di far menzione dell' attentato contro la vita del Re... Non mi lasci neppur mancare un esemplare del Ristretto del Processo, o sentenza che contro il sudetto Padre fu letta nell'Atto di Fede, quando sia per stamparsi come pare che accenni la Relazione».

13. ASV, Segretaria di Stato, Spagna, vol. 431, 11 de Junio de 1761. 
Continuaba escribiendo Torrigiani que no se pedía más que se siguiera observando lo que hizo Su Majestad Católica cuando recibió la investidura de Clemente XIII. El Rey Fernando no debía alejarse del ejemplo del Rey Católico. El Nuncio recibía instrucciones para presentar una queja al rey español con la mayor rapidez porque «se non si emenda il fatto della Reggenza con rinovare la Riversale, il diritto dell'Investitura, il censo, in somma, il Regno di Napoli é perduto per sempre dalla Chiesa Romana. Questo primo esempio sarà confermato tra sei anni col secondo, quando il Re Ferdinando giunto all' età maggiore, dovrà ratificare la prima reversale, il secondo farà strada agli altri... finché resti esente quel Regno dal diretto Dominio del Papa» ${ }^{14}$.

A este problema, se añadía el que se produjo en España tras la aparición del Breve condenatorio de la traducción italiana de la obra de Messenguy, Exposición de la Doctrina Cristiana. Publicada en francés, la obra negaba la infalibilidad papal y atacaba a los jesuitas. A pesar de haber sido condenada dos veces en el pontificado de Benedicto XIV, se publicó traducida al italiano en Nápoles sin considerar las correcciones de la censura (1758-60).

Las protestas de los jesuitas no tardaron en aparecer. Para evitar la condena papal, se reeditó la obra aprovechando el consentimiento de Tanucci. Tras el examen de una comisión de diez teólogos, que resolvieron negativamente sobre el libro, Clemente XIII publicó el breve condenatorio del mismo el 14 de junio de 1761. El Inquisidor General de España, Quintano Bonifaz, publicó el breve a pesar de la prohibición que había recibido por orden del rey ${ }^{15}$. Como escribió el propio Torrigiani a Pallavicini el 27 de agosto de 1761 :

"Questa pubblicazione colla trasgressione di Monsignor Inquisitore al Regio comando, formano il soggetto delle altissime querele di codesta Corte contro di lei, attribuendo l'una e l'altra ad una segreta intelligenza che ella avesse coll'Inquisitore».

El Nuncio español al verse directamente implicado en el asunto escribió una nota en la que le presentaba sus excusas por la publicación del Breve pontificio. Y esto fue recriminado por Torrigiani pues:

«Loda il Santo Padre la dilei buona intenzione di procurare con questa scusa la sollecita restituzione della primiera buona armonia; ma non resta sodisfatto, che cosí subito abbia ella ceduto alla forza di quelle ragioni, le quali aveva esposte a Sua Maestà, $e$ che se non erano giunte ad appagarlo e convincerlo, convincevano pero chiunque avesse voluto rettamente, e imparzialmente giudicar dell'affare $»^{15}$.

El 1 de octubre de 1761, Torrigiani comunicaba al Nuncio que el Papa quería sostener la inocencia de su actuación y al escribir esta carta en la que pedía excusas se había acusado a sí mismo.

El problema se complicó todavía más con el destierro del Inquisidor de la Corte y la negativa a recibir al Nuncio por parte de Su Majestad Católica. En Nápoles, en Roma y también en Francia, se pronosticaba la expulsión del Nuncio y la ruptura abierta

\section{Ibídem.}

15. MESTRE, A. «Religión y cultura en el siglo XVIII español» en Historia de la Iglesia en España, BAC, Tomo IV, pp. 658-659.

16. ASV, Segretaria di Stato, Spagna, vol. 431, cifra del 8 de Octubre de 1761. 
entre España y la Santa Sede. Además, el Consejo de Castilla estaba iniciando una consulta sobre el ejercicio de las facultades de los Tribunales de la Inquisición y de la Nunciatura. Torrigiani manifestó la preocupación pontificia por este hecho si bien:

«Se la cosa si fosse dovuta esaminare in una Camera di Santa Chiara, non avrebbe tardato un momento a scoppiare un fulmine il più terribile, onde lei si accorga da questo solo quanta è la diversità che passa fra le massime di Napoli e quelle di Spagna. I vescovi anche di codesti Regni sono di altro credito, e di altro petto, che quelli del Regno di Napoli, e pero ella interessi anche questi nei passi che ha fatti, e che farà per riparare que'colpi più forti che si pensasse di dare alla Podestà Pontificia, e alla Giurisdizione Ecclesiastica»" ${ }^{17}$.

En el pensamiento del Secretario siempre estaba muy presente el caso napolitano con sus acciones contra el poder pontificio. Y efectivamente, en Nápoles se había prohibido a los Obispos imprimir cualquier escrito sin la revisión y examen de la Cámara Real (cifra del 5 de noviembre de 1761). Y además, se imprimió de nuevo la orden para la ejecución de la carta de 1746 del marqués Fraggianni ${ }^{18}$ a los Obispos y Arzobispos del Reino sobre el modo de proceder en las causas de fe. El 19 de Noviembre de 1761 , Torrigiani comunicaba a Pallavicini lo siguiente:

«Un altro strepitoso incidente poco é mancato che non sia occorso in Napoli... forse sarà nota a V.Illma. la consulta che fece il Signor Marchese Fraggianni contro l'Enciclica e il Breve di Nostro Signore proibitivo del noto Catechismo. Questa consulta é uno de'piu insolenti, temerari...scritti che possano mai uscire alla luce. Congiuntamente alla consulta girava pure una Prammatica... della istessa tinta della consulta medessima... quando si seppe con sicurezza da Monsignore Nunzio in Napoli, che già la Prammatica era sotto il torchio per esser pubblicata colle stampe d'ordine regio... ottenne la sospensione della stampa suddetta».

Tanucci escribió al Rey Católico para obtener el permiso para publicarla. Torrigiani, furioso, comentaba el 26 de noviembre de 1761, la inutilidad de continuar insistiendo en la referida publicación porque los Obispos no habían hecho ningún uso del documento pontificio.

Pero en España, a pesar de la gravedad del caso, se podía contar con la ayuda de los obispos a los que el Nuncio debía hacer participar activamente en el conflicto, convirtiéndolos en sus aliados. El 1 de diciembre de 1761 Carlos III escribió una carta a Clemente XIII en respuesta de la anterior que el Pontífice le remitió para exponerle su pesar por las molestias que le había producido el asunto de la Bula condenatoria del Catecismo de Messenguy. En ella, el Rey manifestaba su deseo de olvidar el asunto y restituirle al Nuncio toda su confianza. Pero a la vez, le avisaba de que había encargado al Consejo de Castilla una consulta para «establecer varias reglas para afianzar aquellos importantes objetos, llevando en ellas por principal norte el respeto debido a la Silla Apostólica y a Vuestra Beatitud» ${ }^{19}$.

17. Ibídem, 15 de Octubre de 1761 .

18. Nicola Fraggianni (1686-1763) fue uno de los más notables personajes del Reino de Nápoles. Jurisdiccionalista y anticurialista, fue secretario del reino nueve años (1724-1733) y consultor en Sicilia desde 1734. En 1740, sustituyó a Carlo Danza como «capo ruota» del Sacro Regio Consiglio y en 1742, fue nombrado delegado de la real jurisdicción.

19. ASV, vol, 431, Carta de Su Majestad Carlos III al Santo Padre Clemente XIII. 
La carta regia no produjo en el ánimo del Secretario ni en el pontificio ningún alivio. Para Torrigiani:

«La lettere che ha egli (el Papa) ricevuta dal Re, e che io qui le accludo, benché concepita ne più rispettosi termini, non é atta in conto alcuno ne a mitigare il suo cordoglio, ne a diminuire la ferita... che in codesti Regni si è fatta all'autorità del Papa, e della Chiesa» ${ }^{20}$.

En la misma cifra, se recoge la noticia de que el Nuncio había recibido un billete de Ricardo Wall en el que se exponían las resoluciones reales respecto a la publicación de los documentos que llegasen de Roma. Éstas eran funestas para la autoridad papal. Torrigiani se mostraba ansioso por conocer cómo se recibiría la noticia por los obispos españoles, y sobre todo el Inquisidor General y su Consejo, «il quale quanto più si vuole esentato dall'autorità di Roma, tanto più si soggetta a quella del Re». Al final, el Rey recibió al Nuncio y perdonó al Inquisidor General. Pero todo este suceso conmocionó a la Santa Sede que no daba crédito a la actuación del rey Carlos y su severidad a la hora de aplicar el «regio exequatur». Como refiere Torrigiani en su cifra del 24 de diciembre de 1761 :

«Dalle notizie che V.Illma. ce ne aveva date (respecto a la piedad del rey y su deseo de agradar a la Santa Sede) non sapevamo concludere tanto funeste conseguenze».

La situación internacional no dejaba de estar presente en la correspondencia de estos dos personajes. En la cifra del 30 de abril de 1761, Torrigiani escribía a Pallavicini sobre la posibilidad, que ya se contemplaba en 1760, de la celebración de un Congreso de Paz. Ahora parecía más próximo el Tratado, y se hablaba de Augsburgo como la ciudad elegida para las negociaciones de los ministros plenipotenciarios ${ }^{21}$. Roma seguía deseando estar presente en este Congreso, a pesar de que se había decidido no contar con la intervención de los países neutrales ${ }^{22}$. Incluso, la Santa Sede preparó una estratagema para poder cumplir su objetivo, en vista de las dificultades que de todas las Nunciaturas de las Cortes europeas se les comunicaba ${ }^{23}$. Junto a esta pretensión, era básico para Roma conocer las alianzas entre las distintas Cortes europeas. Así, por ejemplo, ocurría con el posible tratado entre Francia y España. En la cifra del 26 de noviembre de 1761, escribió el Secretario:

«É cosa molto incerta, a parer mio, il decidere se vi sia, o no pendente il maneggio d'un trattato d'Alianza defensiva ed offensiva tra la Francia e la Spagna. Resto inteso di

20. ASV. Ibídem, 24 de Diciembre de 1761.

21. Se había difundido la noticia de las declaraciones hechas en París el 26 de marzo por los representantes de la Emperatriz-Reina, de la Emperatriz de Rusia, del Rey de Francia, del Rey de Suecia y del de Polonia para reunirse en Ausgburgo. Las Cortes de Londres y Berlín respondieron con la misma declaración el 3 de abril. (cit. MAIORINI, M.G. Epistolario di Bernardo Tanucci, Vol.IX, Roma, 1985, p. 543).

22. Son bastante significativas las palabras de Bernardo Tanucci sobre esta pretensión de la Santa Sede: «Torno a dire che il Re Cattolico non penserà ad Augsburg, se non vi sarà invitato; e che persisto nella opinione di che né Genova, né Turino, né Venezia, né Napoli devano trovarsi nel Congresso. Di Roma non penso, che non è un animale naturale; come non mi mescolo delle chimere, dei centauri, o ipogrifi, tale essendo Roma in rango di potenze, cioè un ente di ragione, e un prodotto della fantasia, e sogno di febbricitante» en MAIORINI, M.G. Op.cit, p. 879.

23. Tanucci, de nuevo, nos da la referencia. En una carta dirigida a Caracciolo en Turín escribe: «Chi vuol andare al Congresso vada... I"italiano che vi andrà sarà la fantasia di Boccaccio, che a coda ritta venne, a coda ritta se ne andò. Questa fantasima, la quale finalmente non vi farà una figura decorosa, meglio che tocasse essere a quel canonico Carampi che, per ordine di Roma, finge di visittare un monastero... e di là vuol farsi trovare in Augusta...» en MAIORINI, M.G. Op.cit., p. 905. 
quanto V.Illma. mi ha riferito su questo proposito... e pare che... non possa far riguardare come vicina una rottura tra la Spagna e l'Inghilterra. Da Parigi... l'ammettono ma forse può essere o che sia una vana lusinga de'Francesi, o sia ancora... per darlo ad intendere agl'Inglesi...».

Todos estos importantes asuntos continuaron siendo el centro del interés de la Secretaría de Estado Vaticana en el siguiente año.

c) 1762

El año de 1762 no comenzó demasiado bien para los intereses de Roma. A principios de enero, veía la luz la Pragmática del Exequatur por la que todo documento pontificio debía ser examinado antes de su aprobación por el Consejo de Castilla, función que llevaba a cabo anteriormente la Inquisición. La Santa Sede había decidido esperar antes de llevar a cabo alguna actuación. El 28 de enero de 1762, Torrigiani refiere al Nuncio Pallavicini cómo el Santo Padre, rompiendo el silencio ante el decreto de Su Majestad, mandó llamar a Manuel de Roda para:

«nei termini più amorevoli, e con apertura di cuore gli palesò il suo grave rammarico per veder cosí violata l'ecclesiastica libertà, cosí avvilita, ed offesa la potestà della Santa Sede col Decreto... per primo passo ne escriveva una lettera a S.M.Cattca., sperando da Lui il rimedio, incaricando lo stesso $D$. Emanuele a cui la consegnava per farle giungere alla mani della Maestà Sua».

El Secretario envió una copia de dicha carta pontificia al Nuncio y además, le añadió la copia de un mensaje escrito por él mismo al ministro Wall. El Nuncio debía tener conocimiento de estos escritos y, además, tratar de hablar con el Padre confesor, al que el Papa también escribió posteriormente.

Es interesante detenerse en la carta que Clemente XIII dirigió a Carlos III. En ella, tras agradecerle su «olvido» respecto a la situación creada por el Breve de condena del Catecismo de Messenguy, le remarcaba que los medios que ha establecido el Consejo, atentaban el orden de las potestades y la autoridad de la Iglesia, que se veía sometida ante la del siglo:

«las circunstancias de los tiempos exigen, Sire, que M.V. abandonados los consejos de los hombres vuelva más que nunca los ojos al cielo... ${ }^{24}$.

La carta que Torrigiani escribió a Wall tenía el mismo tono que la anterior e insistía en el trastorno que suponía para los pueblos ver deprimida de esa forma la autoridad dada por Jesucristo a su Vicario. El Secretario, además, no cesaba de enviar información al Nuncio español para que éste estuviera preparado a la hora de defender los intereses de Roma ante el establecimiento del «exequatur». Así, por ejemplo, en la cifra del 11 de febrero de 1762, escribía a Pallavicini:

"Le accludo poi copia di due Articoli dei Concordati fatti tra la Santa Sede e la Corte di Spagna, in proposito dell'exequatur, revista, o esame, o altro impedimento che si volesse dare all'esecuzione delle carte di Roma. V.I. osservi e consideri quanto contrarie a patti cosí solenni sono le regole ultimamente da Sua Maestà su tal materia prescritte».

24. ASV, Ibídem, «Lettera scritta dalla Santità di Nostro Signore Padre Clemente XIII a Sua Maestà Cattolica», Cifra del 28 de enero de 1762. 
Los obispos españoles no dejaron de manifestar su disgusto ante el nuevo reglamento:

«Ho gran piacere di sentire, che dalle note tre Curie ecclesiastiche siansi fatti dei reclami contro le nuove regole stabilite per le carte di Roma. Seguiti V.lllma. a star sull'intesa, se altre daranno dei passi consimili, e veda d'appurare il netto dei ricorsi delle Curie di Cartagena, e Malaga, e mi dica in oltre, se l'esenzione del Passe che S.M. ha acordato nei due casi particolari al Vescovo di Majorca, possa sperarsi che sarà estesa anche ad altri casi di simil genere» ${ }^{25}$.

La gravedad del asunto motivó que Roma decidiera mandar a España un religioso que ayudara a Pallavicini en su difícil tarea al frente de la Nunciatura española. Este religioso, en principio, sólo llevaría consigo los diferentes papeles y representaciones que la Santa Sede había redactado ante el abuso que suponía la Pragmática española. Una vez en su destino, bajo la directa dependencia del Nuncio, debía prestarle ayuda para escribir sobre esta materia y actuar, si era necesario.

Esta idea sugerida por Torrigiani, sin embargo, no terminó de gustarle al Nuncio, lo que se observa en el siguiente párrafo:

«É primieramente in ordine all'idea comunicatale coi miei numeri degli 11 scorso devo assicurare V.Illma., che essa non é venuta nell'animo di Nostro Signore per alcuna diffidenza dell'abile e diligentissimo di lei ministero, ma solamente per procurare all'importantissima causa che si deve trattare, tutti i possibili soccorsi... Ma... il prender consiglio in un cosí scabroso maneggio da persone informate... é stato sempre praticato da ogni abile e accreditato ministro. In Spagna forse V.Illma. non ne avrà alcuno... V.Illma. ben vede che la di lei estimazione resta cosi al sicuro... ${ }^{26}$.

No sólo era este problema en España el único que merecía la atención de Roma. En 1762, el arresto en Barcelona del portador del correo papal, Ottavio Bandini, provocó un incidente diplomático entre ambas cortes. Los funcionarios reales que lo detuvieron inspeccionaron toda la correspondencia y su carga, pues fue acusado de contrabando. Y además, estuvo en prisión y se le confiscó parte de su equipaje. En la cifra del 15 de abril de 1762, Torrigiani confesaba:

«A me pare, che la reale risoluzione sia assai rigorosa, trattandosi d'un corriere, $e$ certamente se noi dovessimo arrestar $i$ corrieri per le robbe di contrabando che seco portano, saressimo ogni giomo alle mani coi Ministri estere per simili controversie».

El Nuncio siguiendo las instrucciones de Roma, insistió para que se restituyeran las mercancias requisadas a Bandini y para que se satisficiera la ofensa recibida. Pero ante la aparición de nuevos asuntos que reclamaban toda la dedicación del Nuncio y ante la certeza de que ni el propio correo sabía justificarse, el 3 de junio de 1762, Torrigiani era claro:

"Dell'affare del Bandini non ocorre far più parola: nè egli merita la protezione nostra, nè vogliamo prender una briga per un affare, in cui ci si potrebbe dar torto».

La guerra europea seguía ocupando la correspondencia. Apenas comenzó el año, Roma ya tenía noticia de la ruptura entre España e Inglaterra y, además, el 7 de enero de 1761, el Secretario escribía:

25. ASV, Ibidem, Cifra del 24 de junio de 1762.

26. ASV, Ibidem, Cifra del 23 de Diciembre de 1762. 
"A Roma già é pervenuto il Trattato tra la Francia e la Spagna, segnato li 15 Agosto, e contenente 28 Articoli. Non essendo però questo che un puro Trattato di Famiglia, $e$ di Alleanza difensiva, da avere effetto solamente dopo la Pace generale, lascia luogo a credere, che siavene alcun altro che abbia allarmato gl'Inglesi, ai quali la Spagna, a costo ancora della rottura, non ha voluto comunicarlo».

Los temores de Torrigiani se confirmaban. Y además, estos hechos tenían repercusiones en asuntos de otra índole. Así, en la cifra del 28 de enero de 1762, aparecía recogida otra consecuencia de la entrada de España en la contienda.

«Dal foglio che V.Illma. mi ha trasmesso coi suoi numeri..., ho rilevato la proibizione dell'ingresso d'ogni mercanzia di qualunque genere, che provenga dai Domini Brittannici, e particolarmente del Baccalà... per la mancanza di questo genere si sia fatta a Nostro Signore l'istanza per dispensare quattro giorni d'ogni settimana nella Quaresima... nei Regni del Re Cattolico delle carni. Questa grazia é già stata da Nostro Signore accordata...».

La situación venía a complicarse por la posición que debía tomar Portugal. En Roma, las noticias que se esparcían daban por seguro la alianza de esta Corte con Inglaterra, para protegerse así de las armas españolas. Torrigiani manifestaba su temor en la cifra que dirigía al Nuncio el 4 de febrero de 1762 pues:

«A Napoli si fanno preparativi di difesa, e tutti gl'Inglesi s'assentano dal Regno, e l'istesso Ambasciatore ha disdetto la casa, onde si crede che possa ricever ordine di partire. Se così é dunque anche l'Italia sarà involta in questa Guerra».

Los acontecimientos seguían precipitándose y ya en la cifra del 27 de mayo de 1762, el Secretario agradecía a Pallavicini:

«quanto... mi ha significato e in quanto concerne la Guerra già cominciata nel Portogallo».

Efectivamente, desde abril de 1762, España y Portugal estaban en guerra. En este momento surgió un nuevo problema en la Nunciatura española. Clemente XIII determinó que Pallavicini debía acompañar al rey español en las campañas militares, pero sólo en el caso de que éste agradeciese esta intención. Torrigiani, no obstante, advirtió al Nuncio que, si en el caso de acompañar al rey tuviese que ir a los estados de Portugal, era aconsejable, debido a la ruptura diplomática de la Santa Sede con esa corte, que estuviera a su lado en calidad de embajador y sobre todo sin usar sus prerrogativas de Nuncio, que se limitaban al territorio español. Esto, confesaba el mismo Secretario en su cifra del 22 de abril de 1762, evitaría que el rey de Portugal se exasperase todavía más con Roma.

Oeiras invocó la alianza anglo-portuguesa, tras retirar a su embajador en Madrid. Durante un corto período, algunas áreas fronterizas fueron ocupadas por los ejércitos españoles y los ingleses abastecieron a los portugueses con suministros y jefes militares (General Burgoyne) ${ }^{27}$. Pero a pesar de la ocupación de Braganza, Chaves y parte de Beira por el Rey Católico, «Ora però $i$ pensieri di tutti sono rivolti alla pace e non si dubita de'Preliminari concordati tra la Francia e l'Inghilterra» ${ }^{28}$. La ocupación inglesa de La Habana vino a complicar la posibilidad de una cercana paz.

27. MILLER, S.J. Portugal and Rome c. 1748-1830. An aspect of the Catholic Enlightenment, Roma, 1978, p. 131 .

28. ASV, Ibidem, Cifra del 16 de septiembre de 1762. 
Las negociaciones continuaban pero el 18 de noviembre de 1762, Torrigiani se lamentaba de la siguiente manera:

«Si é giunta la nuova della sottoscrizione dei Preliminari di pace, stiamo attendendo di sentirne le condizioni. Dio faccia che la perdita dell'Havana non abbia peggiorato quelle che risguardano codesta Monarchia. Si dice che possa esservi la cessione della Florida. V.I. non mancherà di darni tutte quelle notizie che potrà penetrare».

Motivo de inquietud para la Santa Sede era la protección en la isla de Menorca de la religión católica. La isla estaba bajo el dominio inglés desde 1708. Ante el tratado de paz que debía establecerse, la jurisdicción e inmunidad eclesiástica debía permanecer, como hasta el momento, protegida como lo estaba por el Artículo V del Tratado de Madrid.

La guerra, por tanto, parecía estar entrando en una nueva fase y se encaminaba hacia el cese de las hostilidades. Pero no ocurría así con el Reino de Nápoles, que seguía amenazando con sus actuaciones al poder pontificio. El marqués Fraggianni fue el que condujo con mayor fuerza la batalla suscitada con el Catecismo de Messenguy y del exequatur. Éste envió una carta circular a todos los Obispos del Reino en la que se les comunicaba que las bulas y breves papales pasaban a estar sometidos al pase regio. Este hecho para Torrigiani no era más que «il frutto dei nuovi ordini di Spag$n a{ }^{29}$. Igualmente, se prohibió a los Obispos la realización de cualquier impresión sin el permiso previo de la Cámara Real.

Torrigiani apenas podía dar crédito a todas estos ataques. Y además, de Nápoles llegaba una nueva afrenta. El librero e impresor Pagliarini había sido detenido en Roma en 1760. Toda clase de rumores se habían extendido sobre el motivo de dicho encarcelamiento en las cárceles de la Inquisición. Se hablaba de que tenía en su poder libros prohibidos. Otros rumores le apuntaban como el impresor de las Reflexiones de un portugués sobre el memorial presentado por los P.P. jesuitas... (1758) y el Apéndice a las reflexiones... (1760). E incluso, se le imputaba la impresión de I lupi smascherati.. (1761), terrible ataque a los cardenales romanos y la Compañía. Estas impresiones se habrían realizado en el Palacio del embajador de Portugal, Almeida. Éste consideró que la acción vulneraba la inmunidad diplomática. A pesar de los intentos de Portugal por obtener el perdón, pasó un año en la cárcel y fue condenado a siete años de galeras. El Papa le perdonó en 1762 y fue colmado de honores por Portugal ${ }^{30}$. Pasó a Nápoles, recibiendo una pensión de la corte portuguesa. Instaló su negocio de impresión en Lisboa (1763) especializándose en traducir documentos en italiano para el gobierno ${ }^{31}$. Y como refería el Secretario en su cifra del 18 de febrero de 1762:

«Il Signor Cardinale Orsini ricevette ordine dal Signore Marchese Tanucci di far partire immediatamente per Napoli il Libraro Pagliarini. Lo eseguì l'Eminenza Sua con altissimo mistero ${ }^{32}$ e segreto... Sarebbe però poco male, che il Signor Marchese avesse prestata la sua mano ad una cosa di dispiacere della nostra Corte, ma il peggio é che ha voluto farne anche trionfo... non mostra di curarsi molto della sua amicizia».

29. ASV, Ibídem, Cifra del 7 de enero de $\mathbf{1 7 6 2 .}$

30. VENTURI, F. Settecento riformatore, Tom. II, Torino, pp. 26-27.

31. MILLER, S.J. Op.cit., pp. 132-133.

32. Efectivamente, fue nombrado secretario de la legación portuguesa en Nápoles, con un sueldo de 12000 cruzados (cit. en VENTURI, F. Op.cit, p. 27) 
El Nuncio debía hacer llegar al Rey Católico toda la indignación ante la participación en el hecho de un cardenal ministro del Rey de las Dos Sicilias en la partida de Pagliarini, que podía hacerlo cuando lo deseara. E igualmente, debía recalcar que en caso de que España llegara a mediar en una posible reconciliación entre Portugal y Roma, en ningún momento tendría que contemplarse como condición preliminar el nombre de Pagliarini. Los esfuerzos mediadores de España se reiniciaron tras la guerra luso-española ${ }^{33}$. Lo cierto era que el Rey de Portugal se negaba a admitir la intervención española en el conflicto, como afirmaba Torrigiani en la cifra del 3 de junio de 1762. A ello, se unía la pretensión de Nápoles de que fueran presentadas a los ministros de la Cámara Real las cartas de los Superiores regulares de Roma para darles así el visto bueno. Wall sugirió al Nuncio la elaboración de una representación a la Corte de Nápoles, a lo que el Papa se negó al no parecerle oportuno. Además, en una cifra del 17 de junio de 1762, el Secretario era claro respecto a Ricardo Wall. Al saber por el Nuncio que había mantenido una conversación con el ministro sobre las posibles medidas que se decía en España, se iban a tomar contra el excesivo número de clérigos y regulares, afirmaba:

«Non so approvare, che per aver sicura certezza... abbia V.Illma. fatto capo dal Signor Wall, e lo abbia positivamente interrogato su questo punto. Qualunque Vescovo o Vicario, e qualunque Provinciale tra Regolari, poteva fornirle quella notizia che ricercava... L'entrar in discorso di tal materie co'Regi Ministri, che sono sempre mal disposti per le cose eclesiastiche, e che in tempo di guerra sempre più di mal'occhio devon vedere il copioso numero de'Chierici e de Regolari, non può produrre altro effetto, che quello di fargli venir voglia di eseguir quei progetti,... Quello però che più precisamente le inculco è di non rimettere in discorso questo affare col Signor Wall».

Wall, por tanto, no contaba con la confianza de Roma. Sin embargo, lo que sí hizo Clemente XIII fue enviar un Breve al Rey de Nápoles y una carta al Rey Católico donde le manifestaba la serie de agravios napolitanos. Carlos III contestó al Papa el 16 de Noviembre de 1762. En su respuesta, el Rey Católico explicaba que debido a su renuncia al Reino no podía intervenir en asuntos que debían examinarse por su propio soberano, ministros y tribunales. Lo único que admitía poder hacer era reflexionar sobre los agravios expuestos que para él no eran más que consecuencias lógicas de las órdenes dadas por Don Carlos cuando reinó en Nápoles.

El único compromiso que tomaba era el de «reiterar al Rey mi hijo los saludables consejos que le tengo dados, y que observa... con escrupuloso cuidado a la conservación de los derechos de la Iglesia y de la Santa Sede, bien asegurado de que por parte de Vuestra Beatitud y de su mministerio, se atenderá igualmente a que no se ponga en embarazo alguno en el exercicio de las Regalías de aquel Reino, ni de las máximas que se consideran indispensables para mantener el buen govierno y la tranquilidad de los Pueblos que Dios le ha encomendado» ${ }^{34}$.

Esta respuesta no podía satisfacer a la Santa Sede. De esta forma, el Papa tomó la determinación de dirigirse directamente a la Regencia de Nápoles para exigir el re-

33. Pallavicini pensaba que el tratado de paz entre España y Portugal era el momento oportuno para la intervención en el conflicto de Carlos III (en MILLER, S.J. Op.cit., pp. 139-140).

34. ASV, Ibídem, Carta de Don Carios, Rey de las Españas, de las Dos Sicilias, de Jerusalén etc. al Santo Padre Clemente XIII. 16 de Noviembre de 1762. 
paro a los agravios sufridos. Torrigiani envió una memoria a Pallavicini que a la vez serviría para responder al Rey Católico, el cual parecía desear que se tratase este asunto directamente entre el Papa y el Ministerio napolitano.

En este delicado momento, esperando que el Nuncio napolitano presentase la copia de la memoria de los agravios a la Regencia, aparecieron (cifra del 30 de diciembre de 1762) tres impresos en Nápoles atribuidos a Monseñor Francisco Antonio Bonaventura, Obispo de Nusco. El Obispo negaba su participación en estos escritos, considerados injuriosos para la Santa Sede y el Papa. Inmediatamente, se ordenó al Nuncio Locatelli presentar una queja ante Tanucci, pues era lo único que faltaba en Nápoles para dar argumentos y justificaciones a los ataques contra Roma.

Y no acababan aquí las penas de Torrigiani respecto a Nápoles. Bitetto, el noble napolitano no se daba por vencido y en la cifra del 20 de mayo de 1762 , se quejaba amargamente de que la causa (mantenida entre el barón y la Cámara Apostólica por la remisión de una deuda) a pesar de haberse remitido a Roma, no avanzaba. Y aún más, era considerada por Tanucci «non... per una lite particolare, ma per un interesse di Stato... Da questa fumata noi ci aspettiamo... amarezze e travagli...».

El Papa, desesperado, había decidido recurrir a la clemencia y ofreció a Bitetto abandonar la vía de la justicia, resarciéndole la deuda. El 24 de junio de 1762, el Secretario comunicó al Nuncio español:

«... come Nostro Signore colla sua generosità abbia dato fine all'affare del Baron di Bitetto. Ho piacere che siasi anche in questa maniera uniformata la Santità Sua al suggerimento che leggo ne'suoi numeri degli 8 corrente, e con uniformità tanto maggiore, quanto che non di una sola parte, ma di tutto il prezzo del residuo dell'olio aggrazierà benignamente il Duca, ora che egli ne ha già fatta presentare la supplica».

Y como el propio Torrigiani confesaba:

«Questa condiscendenza però del Santo Padre, usata solamente a riguardo de'premurosissimi uffici della Corte di Napoli, non spero che possa meritare da quei Ministri una maggior facilità ne'nostri affari, e una cessazione da quegli aggravi che ogni giorno ci fanno sentire contro i diritti della Chiesa e della Santa Sede».

Éste era el panorama complicado que presentaba la correspondencia del Secretario en 1762. El siguiente año no iba a resultar ni mucho menos tranquilo para las relaciones entre Roma y España. Y tampoco, como también se lee en las cifras, en las que se establecieron entre la Santa Sede y el resto de los países europeos.

\section{CONCLUSIONES}

El estudio de las cartas que, desde 1758 a 1762, envió el Secretario de la Santa Sede al Nuncio apostólico en España, ofrece un gran interés a la hora de elaborar un cuadro de las complejas relaciones que se establecieron entre Roma y la Corte española, en la segunda mitad del siglo XVIII.

Son varios los temas cardinales que constituyen el reflejo de las inquietudes que el Secretario de Estado comunicaba al representante pontificio. En primer lugar, y como corresponde a la Nunciatura con la que se trata, aparecía la preocupación del Cardenal Torrigiani por los sucesos de la Corte española, tanto en la política exterior como en su vertiente interna. 
Así, la posición española ante las guerras europeas del momento y su posible mediación ante los problemas continentales suscitaba la curiosidad del Secretario. Pero era básico conocer el funcionamiento interno del gobierno español y su composición. De esta forma, se podían averiguar qué vías eran las más adecuadas para la $\mathrm{Cu}-$ ria romana y cuáles era preciso evitar. Por ejemplo, a juzgar por las expresiones de Torrigiani, el ministro Ricardo Wall no era demasiado proclive a favorecer las pretensiones de la Santa Sede.

Junto a este importante bloque, surge otro gran tema de interés en la correspondencia constituido por los comentarios que el Secretario realizaba sobre diferentes asuntos que tenían lugar contemporáneamente en otras Cortes europeas. Portugal ocupa un importante apartado debido a los acontecimientos que en estos años tuvieron lugar en ese país (ataques de Pombal a los jesuitas, la ruptura con la Santa Sede y la expulsión del Nuncio Acciaiuoli, el acercamiento a Inglaterra en la guerra de los Siete Años que dividía el continente europeo). Francia igualmente aparece en la correspondencia ante la posibilidad de una alianza franco-española que cambiaría el desarrollo de la citada guerra y, sobre todo, los Estados italianos. Es aquí donde Nápoles adquiría gran protagonismo. Las acciones de Tanucci y la Regencia napolitana constituían un constante obstáculo para los planes de Roma. Además, este reino tenía una relación inevitable con el de España por los acontecimientos del momento y el anterior reinado de don Carlos de Borbón.

Torrigiani, lógicamente, expresaba sus quejas ante los ataques que la Santa Sede debía sufrir en todos los territorios y planteaba una serie de cuestiones concretas que atentaban contra la autoridad romana en el marco de la política regalista. Así, la cuestión del Catecismo de Messenguy con toda la tensión que originó en España o el exequatur que llevaban a cabo diferentes gobiernos europeos ante los documentos emanados por Roma constituían graves problemas a los que se tuvo que enfrentar el Pontífice. A ello se unían los intentos de los gobiernos por disminuir el número de religiosos, riquezas y poder del clero en sus territorios.

Pero no sólo se pueden distinguir esta serie de temas en el conjunto documental constituido por la correspondencia. Torrigiani, como portavoz de la Santa Sede, incluía en ella toda una serie de recomendaciones a sus representantes en la Nunciatura de los distintos países católicos europeos. Así, se observa que los Nuncios ejercían una labor diplomática, no exenta de secretos y subterfugios.

Ello les hacía ser considerados por las Cortes como una figura amenazadora y poco proclive a los objetivos regalistas del momento. A priori, las actuaciones de los Nuncios no podían ser contempladas con gran simpatía. Igualmente, el Secretario comunicaba a los Nuncios a través de su correspondencia los reproches ante lo que por la Santa Sede se consideraban comportamientos equivocados en sus acciones.

Todos estos argumentos abarcan la realidad de la época, componiendo el retrato vivo y apasionante de este conflictivo período. España ocupaba un papel de primera magnitud como potencia en el concierto europeo. Y era inevitable que chocase con otra potencia dentro del mundo católico. La relación con Roma, en el pontificado de Clemente XIII, estuvo muy lejos de transcurrir sin sobresaltos. A pesar de que nunca se cuestionó la superioridad del Papa como jefe espiritual de la Iglesia, el regalismo, 
que se esforzaba por incrementar la autoridad del soberano, no podía menos que observar el poder de la Iglesia con grandes reservas.

Fue éste el motor que movió las acciones del gobierno español en estos años. El soberano no podía ver disminuida su jurisdicción por el cabeza de la Iglesia-soberano de los Estados Pontificios. Y los Nuncios eran considerados los instrumentos de la injerencia papal, y por tanto enemigos a cualquier intento de cambio en las relaciones de los diferentes gobiernos con Roma. 